\title{
THE TOXIC FACTORS IN EXPERIMENTAL TRAUMATIC SHOCK. IV. THE EFFECTS OF THE INTRAVENOUS INJECTION OF THE EFFUSION FROM ISCHEMIC MUSCLE ${ }^{1}$
}

\author{
By J. C. AUB, A. M. BRUES, S. S. KETY, I. T. NATHANSON, A. L. NUTT, \\ A. POPE, AND P. C. ZAMECNIK \\ (From the Medical Laboratories of the Collis $P$. Huntington Memorial Hospital of \\ Harvard University at the Massachusetts General Hospital, Boston, Massachusetts)
}

(Received for publication April 9, 1945)

The fundamental hemodynamic disturbances which characterize traumatic shock may be initiated by at least 3 different factors: gross hemorrhage or loss of plasma into a traumatized region, neurogenic and psychogenic elements, and the absorption of toxic materials from traumatized regions. Of these etiologic factors, the local loss of vascular fluid is generally conceded to be of greatest importance $(3,28,31,54)$, while the others can be at best but contributory.

Since the original classical experiments of Cannon and Bayliss (1), the theory of traumatic toxemia has been furthered by two types of experimental evidence. In one, a state more or less resembling clinical shock is produced in animals by the parenteral administration of various extracts of normal or traumatized tissues or by the intraperitoneal implantation of tissue. In the other, attempts are made in various ways to control or limit local fluid loss and neurogenic factors in experimental traumatic shock and to demonstrate that an additional factor, presumably traumatic toxemia, is necessary to explain the results. This approach has been considered in another publication (55) and the present discussion will concern itself only with the first type of experiment.

Many experiments have been reported in which extracts of various tissues were found to have definite vasodepressive or shock-producing properties (56 to 61$)$. Certain techniques $(62,63)$ consist of introducing into the peritoneal cavity of dogs whole or pulped liver or muscle. Observed regularly were hemoconcentration, circulatory col-

${ }^{1}$ This is reprint No. 608 of the Cancer Commission of Harvard University.

The work described in this paper was done under a contract, recommended by the Committee on Medical Research, between the Office of Scientific Research and Development and the Massachusetts General Hospital. lapse, and death within 24 hours. Furthermore, at autopsy the viscera consistently showed congestion, edema, and gastrointestinal hemorrhage. More recently, shock was observed following the parenteral injection of extract of striated muscle, and adenosine triphosphate was implicated as the constituent responsible for these effects (64).

In the experiments cited, there have been no bacteriologic studies, and in only a few has any attempt been made to prevent bacterial contamination during the course of the experiment. The inability to reproduce the results of some of these experiments, when strict aseptic technique was used (65), raises the question as to how many of the positive results reported may have been due to extraneous bacterial contamination.

In many of the cited experiments the criteria of shock do not appear conclusive. They consist either of death of the animal, certain autopsy findings, a fall in blood pressure, or combinations of the three. In some experiments, hematocrit studies have been done in addition and these have u s u a lly shown a marked hemoconcentration. Death and hypotension are hardly pathognomonic of shock, while recent studies in clinical traumatic shock without evident hemorrhage have revealed a falling hematocrit (66).

Dosage, rate, and route of administration are of paramount importance in evaluating the toxicity of any substance, yet these factors appear to have received insufficient attention in experiments on the toxicity of tissue extracts. If one may convert to clinical terms the experiments of one investigator (64), it would require that a large part of the muscle tissue of the body be ground, extracted, and administered in one dose in order for shock to follow. It would be desirable to determine the rate at which substances might be absorbed from a traumatized region and to reproduce that rate 
in the administration of tissue extracts. It is not sufficient to demonstrate that substances obtainable from traumatized tissue are toxic; it must be clearly shown that they are toxic in the form, in the dose, and at the rate of absorption which might conceivably occur in clinical traumatic shock.

In view of these considerations, the remarkable thing about the injection of tissue products is not that they are toxic but that they are so often found to be innocuous. In recent experiments with lymph from traumatized limbs, noxious effects were produced in recipient animals in only 30 per cent of the trials (67). In one series of recipients, normal lymph was found to possess toxic properties in 50 per cent of cases (68). The consistently negative results which have been obtained by another group when bacterial contamination is prevented have already been mentioned (65). Extracts of traumatized limbs were found to cause no blood pressure fall or any untoward effects when administered intravenously in excessive dosage (69). This observation is particularly difficult to reconcile with the thesis that significant quantities of shock-producing factors may be liberated from traumatized regions.

The theory of traumatic toxemia can, therefore, hardly be called established, and it seems that further experimental work is warranted. The muscle ligation technique previously described (14) affords a method for obtaining in large quantities the fluid which effuses from an area damaged by prolonged ischemia. Chemical examination of this fluid (70) indicates that it represents plasma which passes through the damaged capillaries and muscle tissue carrying with it products of cellular disintegration. It seemed reasonable that toxic factors if they exist should be present in such fluid and that a pharmacodynamic study of the effects of this fluid on intravenous administration might be of value.

\section{METHODS}

The operation of muscle ligation, release after 5 hours, and fluid collection as described previously (14) were performed with sterile precautions. The fluid which collected during the 5 hours following release of the ties was centrifugalized and the supernatant fraction frozen and preserved on carbon dioxide snow until used. Before administration, the fluid was thawed, filtered through a few layers of gauze, warmed to room temperature, and administered intravenously over a period of 15 to $30 \mathrm{~min}$ utes. The dose given which approximated $14.7 \mathrm{ml}$. per $\mathrm{kgm}$. exceeded slightly the average output $(12 \mathrm{ml}$. per $\mathrm{kgm}$.) of the 35 donor animals in this series. The animals used were mongrel dogs in apparently normal health, anesthetized with sodium pentobarbital. Blood pressure was recorded continuously by a mercury manometer connected to a carotid cannula containing dilute heparin or 2.5 per cent sodium citrate solution. Cardiac output was determined at intervals using the Fick principle as first used in shock by two investigators (71). Mixed venous blood was obtained from a catheter passed down one external jugular vein with the tip either in or at the level of the right auricle. Arterial blood was taken from a femoral artery by puncture. The bloods were collected and preserved under oil, and oxygen content was determined by the manometric method of Van Slyke and Neill. Oxygen consumption was measured by a calibrated recording spirometer connected to a tracheal cannula. Carbon dioxide was removed by soda lime in the system. Relative total peripheral resistance was calculated from the relationship:

Relative total peripheral resistance $=\frac{\text { Mean arterial B. P. }}{\text { Cardiac output }}$

No attempt was made to calculate the resistance in absolute units since only changes from control values were desired, but in order to permit better comparison between animals of different weights, cardiac outputs were substituted in the formula in terms of liters per minute per $\mathrm{kgm}$. of body weight.

Mixed venous blood hemoglobin concentration was determined photocolorimetrically. When used to measure the trend of hemoconcentration in a given experiment this determination possesses the advantage over erythrocyte hematocrits in that it is independent of changes in erythrocyte size and of such variables as speed and duration of centrifugation, plasma viscosity, and specific gravity. Its use as a gross index of plasma loss seems warranted, although, in common with the great vessel hematocrit, it cannot be said to reflect quantitatively the average body hematocrit.

The recipient animals were observed for a period of at least 5 hours after the injection of fluid. If throughout that time no significant change had occurred in the condition of the animal, the experiment was terminated. Where any change had occurred, observations were continued until the death of the animal. Because of the possibility that the plasma proteins present in the injected fluid might augment the blood volume of a normal recipient and either mask any possible toxic effects or cause harm in itself by mere plethora, in 10 experiments the fluid was reinjected at the end of the collection period into the animal which had produced it. It thus merely partially replaced plasma volume already lost. The results were in no way different from those in which the fluid was administered to other recipients. Gross and microscopic examination of the viscera were made in the majority of animals. Bacteriologic studies which were made on the - fluids are reported in another communication (11). 


\section{RESULTS AND DISCUSSION}

The results are presented in Tables I and II. They divide themselves sharply into 2 groups. In 1 (Table I), the injection of the fluid resulted in a progressive decline in blood pressure and cardiac output, death of the animal usually within 5 hours, and consistent autopsy findings. These are the criteria of shock used in our experiments. The characteristic fall of blood pressure was interesting for it was invariably a distinctly delayed reaction. Some fluids had a mild vasodepressor action which caused a prompt and short fall of blood pressure which rapidly disappeared. The blood pressure then usually rose nearly to the control level. After a delay of 30 to 45 minutes, the shockproducing effect became manifest in a gradual progressive fall in blood pressure. Figure 1 illustrates the blood pressure response of an animal following injection of muscle exudate. In a few instances the rate of blood flow through one femoral artery was measured by means of a modification of an air bubble flow meter (72). In animals showing the other criteria of shock following the intravenous injection of muscle exudate, a significant reduction in the peripheral blood flow was observed, consistent with the reduction in cardiac output.

In the other group (Table II), none of these effects were observed. Even though the results described in the previous paper of this series indicate the dominance of fluid loss, this is good evidence for an additional inconstant toxic factor in muscle exudate which has the effect of producing shock, in spite of increasing the plasma volume by roughly 25 per cent. The effect was obtained consistently in the pooled fluids (number 9) accumulated from 9 dogs, indicating that the effect does not depend on individual sensitivity of certain animals to the toxin.

Examination of the possible sequence of events in the first group of animals indicates that the rapid and progressive decrease in cardiac output precedes, and is the probable cause of, the drop in blood pressure. The progressive increase in total peripheral resistance may be the result of a compensatory peripheral vasconstriction. The reduction in cardiac output, however, is not specifically explained by the data available. It could result from either an intrinsic myocardial change or a decrease in venous return to the heart. The

TABLE I

Positive muscle exudate assays

\begin{tabular}{|c|c|c|c|c|c|c|c|c|c|c|c|c|c|c|c|c|}
\hline \multirow{2}{*}{$\begin{array}{c}\text { Donor dog } \\
\text { number }\end{array}$} & \multirow{2}{*}{$\begin{array}{c}\text { Fluid } \\
\text { number }\end{array}$} & \multirow{2}{*}{$\begin{array}{c}\text { Re- } \\
\text { cip- } \\
\text { ient } \\
\text { dog } \\
\text { num- } \\
\text { ber }\end{array}$} & \multirow{2}{*}{ Weight } & \multirow{2}{*}{ Dose } & \multicolumn{3}{|c|}{ Blood pressure } & \multicolumn{3}{|c|}{ Cardiac output } & \multicolumn{3}{|c|}{$\begin{array}{l}\text { Relative total } \\
\text { peripheral } \\
\text { resistance }\end{array}$} & \multicolumn{3}{|c|}{ Blood hemoglobin } \\
\hline & & & & & I & II & III & I & II & III & I & II & III & I & II & III \\
\hline & \multirow{15}{*}{$\begin{array}{c}9^{* *} \\
9 \\
9 \text { (dial.) } \\
9 \text { (dial.) } \\
9 \text { (prot. } \\
\text { frac.) } \\
9 \\
17 \\
19 \\
24 \\
28 \\
29 \\
148 \\
154\end{array}$} & \multirow{6}{*}{$\begin{array}{l}122 \\
123 \\
128 \\
129 \\
132\end{array}$} & \multirow{2}{*}{$\begin{array}{l}\mathrm{kgm} . \\
11.5\end{array}$} & \multirow{2}{*}{$\begin{array}{c}\text { ml.per } \\
\text { kgm. }\end{array}$} & \multicolumn{3}{|c|}{$m m . \mathrm{Hg}$} & \multicolumn{3}{|c|}{$\begin{array}{l}\text { liters per kgm. } \\
\text { per minute }\end{array}$} & & & & \multicolumn{3}{|c|}{ grams per $100 \mathrm{ml}}$. \\
\hline Pool* & & & & & 134 & 110 & 60 & 0.13 & 0.19 & 0.03 & 1040 & 580 & 2000 & & & \\
\hline Pool & & & 5.0 & 15.0 & 120 & 75 & 60 & 0.10 & 0.02 & 0. & 1200 & 3750 & 3000 & 15.3 & 15.7 & 19.2 \\
\hline Pool & & & 7 & 25 & 130 & 100 & 3 & 0. & 0. & 0. & 1000 & 2000 & 1133 & & & 15.6 \\
\hline Poo & & & 6. & 27. & 138 & 124 & 45 & 0.12 & 0.06 & 0.02 & 1151 & 2067 & 2250 & 13.8 & 14.4 & 13.8 \\
\hline Pool & & & 0 & 15 & 140 & 72 & 40 & 0.15 & 0.06 & 0.01 & 935 & 1200 & 4000 & 16.4 & 17.2 & 18.9 \\
\hline Pool & & 136 & 9.0 & 24.0 & 160 & 138 & 104 & 0.13 & 0.15 & 0.04 & 1230 & 917 & 2600 & 19.8 & 15.2 & 17.2 \\
\hline $148^{*}$ & & 149 & 9.8 & 5.0 & 145 & 50 & 65 & & & & & & & 18.5 & 18.5 & 17.8 \\
\hline 151 & & 151 & 29.0 & 9.7 & 130 & 130 & 32 & 0.03 & 0.0 & 0.0 & 4333 & 3250 & 1600 & 16.7 & 17.2 & 18.3 \\
\hline 172 & & 173 & 12.0 & 15.0 & 142 & 135 & 6 & 0.16 & 0.08 & 0.1 & 888 & 1688 & 3250 & 13.1 & 11.5 & 11.7 \\
\hline $180^{*}$ & & 182 & 6.0 & 15.0 & 110 & 78 & 30 & 0.34 & 0.08 & 0.02 & $\cdot 324$ & 975 & 1500 & & & \\
\hline 181 & & 183 & 5. & 15.0 & 108 & 55 & 35 & 0.12 & 0.05 & 0.05 & 900 & 1100 & 700 & 12.0 & 8.7 & 7.2 \\
\hline . & & 148 & 17. & 11. & 130 & 100 & 6 & & & & & & & & & \\
\hline $154^{*}$ & & 154 & 23 & 22.0 & 120 & 120 & 80 & & & & & & & & & \\
\hline Average & & & 11.5 & $18.9^{* * *}$ & 130 & 99 & 54 & & & & 1300 & 1753 & 2203 & 15.3 & 14.3 & 15.5 \\
\hline
\end{tabular}

* Data incomplete.

** Pooled fluid 9 is discussed in detail in the following paper of this series (23). Following dialysis (dial.), the non-dialyzable portion retained its activity, and the protein fraction (prot. frac.) which salted out from 0.2 to 0.7 saturation with ammonium sulfate was the most highly active. The dosage of these fluids has been calculated from the original fluid involved, and does not take into account losses in toxicity which must have occurred during dialysis and fractionation.

${ }_{* * *}$ Average dose omitting fractionation experiments, $14.7 \mathrm{ml}$. per $\mathrm{kgm}$.

I Before injection. II Immediately after injection.

III Final or 5 hours. 
TABLE II

Negative muscle exudate assays

\begin{tabular}{|c|c|c|c|c|c|c|c|c|c|c|c|c|c|c|c|c|}
\hline \multirow{2}{*}{$\begin{array}{c}\text { Donor } \\
\text { dog }\end{array}$} & \multirow{2}{*}{$\begin{array}{c}\text { Fluid } \\
\text { number }\end{array}$} & \multirow{2}{*}{$\begin{array}{l}\text { Recip- } \\
\text { ient } \\
\text { dog } \\
\text { number }\end{array}$} & \multirow{2}{*}{ Weight } & \multirow{2}{*}{ Dose } & \multicolumn{3}{|c|}{ Blood pressure } & \multicolumn{3}{|c|}{ Cardiac output } & \multicolumn{3}{|c|}{$\begin{array}{l}\text { Relative total } \\
\text { peripheral } \\
\text { resistance }\end{array}$} & \multicolumn{3}{|c|}{ Blood hemoglobin } \\
\hline & & & & & I & II & III & I & II & III & I & II & III & I. & II & III \\
\hline & & & kgm. & $\begin{array}{c}\text { ml.per } \\
\text { kgm. }\end{array}$ & \multicolumn{3}{|c|}{$m m . \mathrm{Hg}$} & \multicolumn{3}{|c|}{$\begin{array}{l}\text { lilers per kgm. } \\
\text { per minule }\end{array}$} & & & & \multicolumn{3}{|c|}{ grams per $100 \mathrm{ml}}$. \\
\hline 135 & 10 & 135 & 20.0 & 14.8 & 94 & 118 & 92 & 0.07 & 0.07 & 0.15 & 1345 & 1690 & 614 & 13.8 & 13.1 & 14.8 \\
\hline 137 & 11 & 137 & 17.5 & 11.4 & 108 & 124 & 130 & 0.08 & 0.16 & 0.16 & 1350 & 775 & 813 & 14.8 & 14.8 & 14.6 \\
\hline 138 & 12 & 138 & 20.0 & 15.0 & 127 & 123 & 132 & 0.10 & 0.04 & 0.04 & 1270 & 3070 & 3300 & 16.7 & 14.2 & 13.6 \\
\hline 142 & 13 & 142 & 20.5 & 7.0 & 100 & 137 & 87 & 0.05 & 0.08 & 0.04 & 2000 & 1713 & 2178 & 14.6 & 15.9 & 17.5 \\
\hline 143 & 14 & 143 & 16.0 & 5.0 & 102 & 90 & 82 & 0.10 & 0.12 & 0.09 & 1020 & 750 & 1000 & 12.4 & 12.5 & 12.6 \\
\hline 145 & 15 & 145 & 19.5 & 10.5 & 120 & 130 & 98 & 0.08 & 0.14 & 0.14 & 1500 & 930 & 700 & 17.7 & 18.3 & 18.2 \\
\hline 14 & 16 & 147 & 20 & 6.7 & 100 & 142 & 108 & 0.12 & 0.22 & 0. & 834 & 646 & 983 & 15 & 15.2 & 15.4 \\
\hline 151 & 19 & 152 & 10. & 15.0 & 95 & 104 & 92 & 0.03 & 0.09 & 0.03 & 3180 & 1159 & 3060 & 15 & 12.4 & 15.1 \\
\hline 153 & 20 & 153 & 27.5 & 14. & 120 & 120 & 135 & 0.03 & 0.04 & 0.04 & 4000 & 3000 & 3380 & 15.2 & 14.6 & 13.8 \\
\hline 166 & 22 & 167 & 6 & 15 & 160 & 95 & 140 & 0.28 & 0.07 & 0.30 & 672 & 1360 & 467 & 13.8 & 13.8 & 14.0 \\
\hline 168 & 23 & 169 & 8 & 15 & 130 & 130 & 130 & 0. & 0.19 & 0. & 620 & 685 & 620 & & 12.7 & 13.0 \\
\hline 171 & 25 & 174 & 13.0 & ? & 136 & 60 & 125 & 0.05 & 0.05 & 0.13 & 2730 & 1200 & 963 & 15 & 11.6 & 12.3 \\
\hline $171^{*}$ & 25 & 175 & 6.8 & 13.0 & 160 & 132 & 142 & & & & & & & & 11.2 & 11.9 \\
\hline 176 & R & 178 & 78 & 00 & 132 & 125 & 118 & 0.18 & 0.15 & 0.1 & 734 & 834 & 842 & 11.7 & 11.7 & 11.2 \\
\hline 17 & 27 & 17 & 6. & 15.0 & 95 & 93 & 130 & 0.13 & 0.23 & 0.17 & 730 & 405 & 765 & 9.6 & 7.2 & 8.0 \\
\hline $214-215$ & 31 & 216 & 6. & 13.5 & 144 & 90 & 125 & 0.40 & 0.09 & 0.13 & 360 & 1000 & 963 & 15.2 & 14.4 & 16.7 \\
\hline 217 & & & 7 & & 16 & 15 & 155 & 0.4 & 0.5 & 0. & 364 & 280 & 80 & & & 12.7 \\
\hline 22 & 33 & 22 & 5 & 15 & 13 & 12 & 135 & 0.34 & 0.17 & 0.1 & 399 & 710 & 900 & 14.2 & 12.7 & 13.4 \\
\hline & & 2 & 5. & 14. & 130 & 130 & 120 & 0.19 & 0.14 & 0.10 & 684 & 927 & 1200 & & & \\
\hline Average & & & 12.9 & 12.0 & 128 & 116 & 120 & 0.16 & 0.14 & 0.13 & 1320 & 1180 & 1315 & 14.1 & 13.3 & 13.8 \\
\hline
\end{tabular}

* Data incomplete.

I Before injection.

II Immediately after injection.

III Final or 5 hours.

latter change could in turn be due either to a loss in blood volume through capillary leakage or a pooling of the blood in dilated vascular beds. The absence of any significant hemoconcentration, however, is evidence against generalized capillary leakage of plasma as an initiating factor in these experiments. In this respect alone do these animals differ from those described by Moon (63); there is, however, a likely explanation for the hemoconcentration which he observed in a large part of his experiments. His experiments consisted of introducing a weighed amount of muscle pulp plus $100 \mathrm{ml}$. of saline into the peritoneal cavity of dogs and subsequently measuring the fluid recovered from the peritoneum at autopsy. While the volume of exudate did not increase much in his observations, it is highly likely that the injected saline solution was replaced by a solution high in plasma proteins. The loss of plasma proteins into the peritoneum may well account for the hemoconcentration. In our observations, the reverse situation holds for we were diluting plasma with an intravenous injection of fluid high in proteins.

The post-mortem appearance of the animals in Group I was similar to that in Moon's experi-

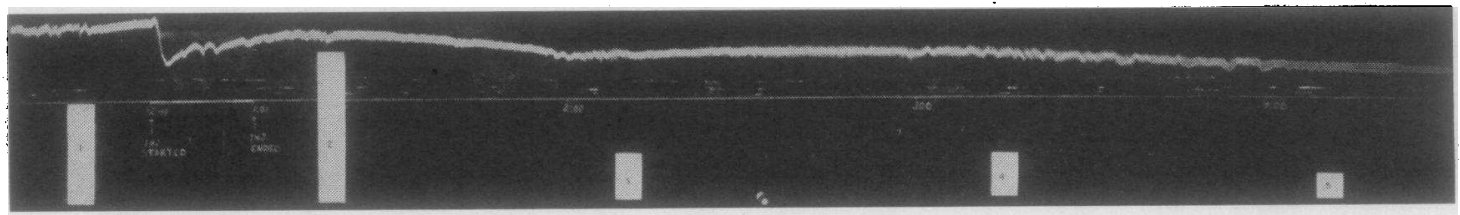

Fig. 1. Kymograph Record Illustrating the Blood Pressure of an Animal Following Injection of Muscle Exudates

The white blocks indicate cardiac outputs taken at various times during the course of the experiment. The first cardiac output taken after administration of the toxin (Number 2) is (in this case) increased, although such was not usually the case. The blood pressure response is a typical one. Cardiac output values are as follows, expressed in liters per minute: Number $1-1.47,2-2.22,3-0.69,4-0.60,5-0.35$. 
ments. There was intense visceral congestion, especially of the liver, together with moderate to marked hemorrhage into the intestinal lumen. This began abruptly at the pylorus, was most marked in the duodenum, and diminished distally.

A consideration of the proportion of positive to negative results in these experiments is illuminating. Of the total of 32 fluids studied, only 9 (or 28 per cent) were found to possess significant toxic properties, while the remaining 72 per cent were apparently innocuous. ${ }^{2}$

If the 9 toxic fluids derived their properties from noxious products of tissue breakdown, it is difficult to see how the other 23 specimens could have failed to contain these substances. All the muscles were subjected to the same degree and duration of ischemia and all the fluids were high in protein content indicating the degree of local capillary damage. Moreover both toxic and nontoxic fluids revealed similar electrolyte composition and the same concentration of proteolytic enzymes (70) indicating similar degrees of cellular breakdown. These considerations and the very inconstancy of positive results from fairly rapid intravenous injection suggest that the positive effects are due to inconstant factors which are not present in all muscles, but are probably an extraneous complication introduced into some experiments.

The possibility presents itself that an explanation for the positive effects in one-fourth of these fluids lies in bacterial contamination. The results of a detailed study of the number and types of

2 Table II does not include the earlier experiments in which the cardiac output was not measured. organisms present in these fluids appears elsewhere (11), and the evidence there presented clearly demonstrates a correlation between the toxicity of a fluid and its bacterial content.

Since the majority of these fluids yielded no evidence of a shock producing factor, it appears warranted to conclude that the usual metabolic breakdown products in anoxic muscles do not produce the vascular changes which precede shock. In our muscle ligation technique, the circulation in the anoxic muscles is usually well reestablished, so that diffusible toxic elements should be present in the circulation as a whole, as well as in the muscle exudate. However, this factor is controlled by the similar results which were obtained when fluids were reinjected into the original donor, as when given to recipient dogs.

\section{SUM MARY}

1. The exudate which accumulates after muscle anoxia was collected and injected into the same or recipient dogs.

2. In three-quarters of such observations, no evidence of shock was observed, while in onequarter of the animals shock was produced by this technique and caused death.

3. The inconstancy of the presence of this toxic factor suggests it is an extraneous agent, not present in the usual cellular constituents and metabolic products found in all muscle exudates. Since the exudates are invariably contaminated with bacteria, it is thought that the toxin may be bacterial in origin.

Bibliography follows Paper VI of this series. 